\title{
CONTEÚDO NÃO CONCEITUAL, HOLISMO E NORMATIVIDADE ${ }^{1}$
}

Ernesto Perini-Santos*

RESUMO A atribuição de conteúdos não conceituais serve à explicação da riqueza da experiência. No entanto, a integração de estados perceptivos, através do tempo e entre diferentes modalidades, necessários à constituição da experiência, parece dever apelar a um vocabulário conceitualista, ao qual se aplicam princípios de racionalidade. Procuro neste artigo contestar esta segunda tese: conteúdos não conceituais são parte da experiência humana, que é organizada de acordo com princípios racionais. A integração da experiência não depende de um vocabulário conceitualista, no entanto, princípios de racionalidade aplicam-se à integração própria à experiência humana. Conteúdos não conceituais são parte da experiência e a eles se aplicam princípios de racionalidade, mesmo se só podem ser atribuídos em um determinado curso de ações e identificados por meio de mecanismos demonstrativos, precisamente porque não são recrutados em conceitos.

Palavras-chave Conteúdo não conceitual, externalismo, normatividade, holismo

ABSTRACT The attribution of non-conceptual contents aims at a finegrained description of experience. But it seems that the integration of different perceptual states, necessary to constitute the experience, demands a conceptual

Professor Adjunto do Departamento de Filosofia da Universidade Federal de Minas Gerais. Artigo recebido em outubro de 2004 e aprovado em novembro de 2004. (epsantos@fafich.ufmg.br)

1 Este artigo foi apresentado no colóquio «Internalismo e Externalismo», realizado em Belo Horizonte, em outubro de 2003.

KRITERION, Belo Horizonte, ${ }^{\circ}$ 110, Dez/2004, p. 238-263 
vocabulary, to which rational constraints apply. In this paper, I argue against this second thesis: non-conceptual contents are part of human experience, organized according to rational constraints. Integration of experience does not demand a conceptual vocabulary, although rational constraints apply to the integration of human experience. Non conceptual contents are part of human experience, and therefore are subject to rational constraints, even if they can only be attributed in a given course of actions, and identified through demonstrative devices, precisely because they are not regimented by concepts.

Key-words Non-conceptual content, externalism, normativity, holism

\section{I}

Um argumento central para a aceitação de conteúdos não conceituais (CNCs), proposto por Gareth Evans, é a maior fineza de conteúdos perceptivos do que dos conceitos que temos a nossa disposição. Não é difícil achar ilustrações para esse fenômeno, por exemplo, na percepção das cores: olhando para o velho tampo de madeira da minha mesa, vejo muito mais nuanças do que conceitos que tenho de tonalidades de marrom. A idéia de que nossa capacidade de distinção pela percepção seja mais fina do que nossa capacidade de distinção conceitual parece evidente - Evans pergunta mesmo se faz sentido pensar que temos tantos conceitos para cores quanto nuanças que somos capazes de distinguir. ${ }^{2}$

Se experimentamos a maior fineza nas distinções pela percepção do que nos conceitos, Gareth Evans impõe condições suplementares para que algo seja parte da experiência: para que um estado informacional com um conteúdo determinado seja parte da experiência, ele deve servir como entrada para a atividade racional, para a aplicação de conceitos e para o raciocínio. ${ }^{3}$ De certa forma, em oposição à defesa de CNCs, essa caracterização da experiência aproxima Evans do que podemos chamar de pólo conceitualista. O que leva a esse

2 "Do we really understand the proposal that we have as many colour concepts as there are shades of colour that we can sensibly discriminate?" EVANS, 1982, p. 229.

3 "But although it is true that our intuitive concepts requires a subject of experience to have thoughts, it is not thoughts about the experience that matter, but thoughts about the world. In other words, we arrive at conscious perceptual experience when sensory inputs is not only connected to behavioural dispositions in the way I have been describing - perhaps in some phylogenetically more ancient part of the brain - but also serves as the input to a thinking, concept-applying, and reasoning system; so that the subject's thoughts, plans, and deliberations are also systematically dependent on the informational properties of the input." EVANS, 1982, p. 158. Ver também: "Molyneux's Question". EVANS, 1985, p. 387. 
movimento é o aparente isolamento de CNCs, isto é, eles parecem só poder fazer parte de algo qualificável como experiência se associados a atividades que à primeira vista só podem ser descritas em termos conceituais.

$\mathrm{O}$ isolamento de CNCs aparece nestes dois aspectos aspectos da atividade racional. O primeiro deles vem do que Evans chama de Generality Constraint sobre conceitos: $S$ sabe aplicar um conceito $F$ somente se, se $S$ sabe o que é para $a$ ser $F$ e conhece um outro indivíduo $b$, então ele entende o que é para $b$ ser $F{ }^{4}$ Um indivíduo pode contudo perceber a diferença entre duas nuanças $n$ e $n$ ' de marrom sem ser capaz de dizer se uma outra região do espaço é $n$ ou $n$ ', o que parece ir contra a condição de generalidade imposta a conceitos. $\mathrm{O}$ isolamento de CNCs corresponde à maior fineza na capacidade de discriminação perceptual do que a nossa capacidade de identificação. Como dizem Jerôme Dokic e Elisabeth Pacherie,

[...] se a posse de conceitos requer uma certa capacidade de reconhecimento, o grau de fineza máximo de nossos conceitos perceptivos corresponderá ao grau de fineza máximo da codificação da memória perceptiva. ${ }^{5}$

Esse traço de CNCs corresponde à limitação na capacidade de transformar em reconhecimento e reidentificação as distinções possíveis na percepção. Como a Generality Constraint é uma condição para conceitos e determinadas distinções na percepção não a preenchem, estas são distinções cujo conteúdo não pode ser associado a conceitos, isto é, cujo conteúdo é não conceitual.

O segundo traço do isolamento vem dos raciocínios feitos sobre a experiência, que utilizam recursos conceituais que justamente parecem não estar disponíveis. Pelo primeiro argumento, inferências com CNCs não poderiam se estender no tempo além do contato perceptual com aquilo de que se fala. Há uma outra limitação para a prática inferencial. Saber que algo é um cachorro implica saber que é um animal, pensar que é da mesma espécie que Totó etc., e nada disso está disponível a quem não tenha o conceito de cachorro. Parece difícil entender o que seria a organização de padrões inferenciais sem conceitos que componham as frases que constituem tais inferências. Os dois pontos estão evidentemente ligados: não podendo se estender no tempo, CNCs não podem ser o ponto de agregação de diferentes crenças em torno das quais

4 EVANS, 1982, p. 100-105; a formulação deve incluir ainda a condição de adequação categorial. Para a aplicação desta constraint na defesa de CNCs para a experiência, ver: MARTIN, 1992, p. 747.

5 "[...] if concept possession requires a certain recognitional capacity, the maximal fineness of grain of our perceptual concepts will correspond to the maximal fineness of grain of perceptual memory encoding." DOKIC; PACHERIE, 2001, p. 198. 
podem se organizar inferências, e talvez nem possam durar o tempo de uma inferência - voltarei a esses dois pontos.

Ao dizer que a experiência perceptual deve servir de entrada para a atividade racional, Evans exige o não isolamento da percepção para que ela seja parte da experiência: a integração daquilo que percebemos parece ser constitutivo da experiência das coisas. O oposto disso seria um estado perceptivo que não estivesse na origem de comportamento algum, que não se ligasse a nenhum outro estado como sendo relativo a uma mesma coisa ou a uma coisa diferente, que não gerasse nenhuma expectativa nem fosse avaliado, por exemplo, como igual ou diferente de uma outra percepção: um tal estado de fato não parece fazer parte da experiência de ver, tocar ou ouvir coisas. Evans sugere que a integração se dá num domínio conceitual. John McDowell apresenta esta tese da seguinte forma:

Segundo Evans, um estado do sistema de informação perceptiva conta como uma experiência apenas se seu conteúdo não-conceitual estiver disponível como "entrada para um sistema de pensar, de aplicação de conceitos e de raciocínios"; isto é, apenas se seu conteúdo não-conceitual estiver disponível para uma faculdade da espontaneidade, que pode aceitar ou recusar racionalmente julgamentos da experiência baseada no estado perceptivo. ${ }^{6}$

A exigência de integração parece razoável, mas não é certo que ela deva nos aproximar do pólo conceitualista. Se à primeira vista parece que a participação de CNCs à experiência depende da sua associação a um domínio que é, de maneira essencial, conceitual, é possível mostrar que essa integração — ou pelo menos alguma integração - não depende da posse de conceitos. Com efeito, Evans nos dá ele mesmo razões para recusar o isolamento de CNCs e nos mostra como propor uma descrição do modo como estão conectados, de tal forma que talvez se deva reconhecer uma experiência que, num certo sentido, pode ser dita não conceitual.

II

A percepção de um objeto por uma dada modalidade sensorial não ocorre isoladamente da sua percepção por outras modalidades, nem da ação do sujeito

6 "According to Evans, a state of the perceptual informational system counts as an experience only if its nonconceptual content is available as 'input to a thinking, concept-applying, and reasoning system'; that is, only if its non-conceptual content is available to a faculty of spontaneity, which can rationally make or withhold judgements of experience on the basis of the perceptual state." JOHN McDOWELL, 1994, p. 49. O caráter kantiano dessa exigência não deve nos espantar, se pensarmos na importância de Strawson para essa discussão de Evans. 
que percebe em relação a esse objeto. A percepção não é tampouco isolada no tempo. Essas diferentes integrações são constitutivas da experiência, como exige Evans, e independentes de conceitos, contrariamente ao que sua descrição de condições impostas a algo para fazer parte da experiência parece dizer.

O caráter supra-modal da percepção se mostra no seu ajuste a sua causa distante, e não a sua causa próxima, isto é, ao objeto independente da percepção, e não às terminações nervosas. Se não fosse dessa forma, se a percepção ocorresse num espaço não integrado, mas específico a uma dada modalidade sensorial, não estaria no espaço de uma ação possível do sujeito. ${ }^{7}$ O sujeito que ouve um som o situa no espaço definido em relação a sua própria posição e pode identificar a direção da qual ele vem. A direção para a qual ele deve virar a cabeça, por exemplo, se quiser olhar para o lugar de onde vem o som, não é o resultado de um cálculo: se esse fosse o caso, duas pessoas escutando um som vindo de uma determinada direção poderiam virar a cabeça em diferentes direções, dependendo precisamente do cálculo feito, o que não faz sentido. ${ }^{8}$ Podemos ainda pensar num argumento análogo a um argumento de Strawson contra os sense data: não há algo que possa ser identificado como um dado anterior e independente a partir do qual tal direção poderia aparecer como resultado. ${ }^{9}$ O que a analogia com o argumento contra os sense data sugere é que o que é percebido é o som vindo de uma determinada direção, e não um dado auditivo não situado no espaço.

A experiência não é tampouco isolada no tempo. Reconhecer o mesmo objeto à medida que nos movemos é parte do que é perceber. O sujeito que vê a mesa a percebe como um objeto que está em determinada posição no espaço, de tal maneira que o modo como ele a percebe depende da sua posição em relação a ela; se ele se mover, vai perceber a mesa de modo diferente, ele pode se colocar numa posição na qual não poderá mais vê-la etc. Esta organização da percepção é chamada por Evans "teoria primitiva da percepção". ${ }^{10}$ Alva Noë observa que alterações nos padrões de contigências sensori-motoras (patterns of sensorimotor contingencies) afetam a capacidade de ver, mesmo se o resto do aparato perceptual permanece intactato. Ele se refere ao famoso experimento do uso de lentes que invertem as imagens: a pessoa volta a ver quando se situa novamente no espaço, recupera os padrões de contigências sensori-motoras. ${ }^{11}$ Essa experiência já havia sido analisada, num outro

7 Cf. BERMÚDEZ, 2001; ver também: EILAN, 1993.

8 “Molyneux's Question". EVANS, 1985, p. 383.

9 STRAWSON, 1979. Ver também: "Mental Entities", de 1952, em QUINE, 1976, p. 221-227.

10 "Things without the mind". EVANS, 1985, p. 261-262.

11 NOË, 2002, p. 185-194. Ver também: NOË, 2001. 
vocabulário, por Merleau-Ponty: não há visão que não seja a visão de um corpo que age, se move no espaço, reconhece o mesmo objeto de diferentes pontos de vista etc. ${ }^{12}$ A ligação entre a percepção e a ação corresponde ao que John Campbell chama de "física primitiva". ${ }^{13}$ Essa compreensão prática do que se percebe, definida de maneira egocêntrica, se opõe a uma representação reflexiva e alocêntrica e pode ser atribuída, por exemplo, a esquilos e bebês, na medida em que a localização do que percebem se faz em relação ao espaço da ação. A integração da experiência em animais não lingüísticos ou prélingüísticos vai além do que pode ser identificado de maneira egocêntrica e se estende, com uma determinada organização, ao que não é percebido num dado momento, como mostra José Luis Bermúdez. ${ }^{14}$

A articulação no tempo entre diferentes estados perceptivos, à medida que aquele que percebe se move ou age, exige uma transição entre estados, ou antes um fluir contínuo que é constitutivo da experiência. Mesmo se resistirmos à aplicação de um vocabulário teórico ("teoria primitiva da percepção", "física primitiva") a alguns desses casos, parece difícil recusar que eles correspondam à exigência da integração da experiência, entre diferentes modalidades, entre a percepção e a ação, com um grau crescente de complexidade, de tal modo que passamos de algo que parece imediato à conexão entre a percepção e sequiências de ações. O conteúdo perceptivo o que é ver a mesa, ver que ela está a tal distância etc. - está numa estrutura holística, como sugere Evans, ${ }^{15}$ estrutura que não depende da posse de conceitos.

A integração da experiência aparece antes da posse da linguagem, tanto na filogenia quanto na ontogenia. Desde muito cedo, a percepção de bebês se organiza de forma supra-modal, de tal maneira que seu centro de interesse, como diz Andrew Meltzoff, é a entidade distante (distal entity), e não o que é próprio a uma modalidade, e isso muito antes da aquisição da linguagem. ${ }^{16} \mathrm{O}$ caráter supra-modal da percepção inclui também a propiocepção, o espaço unificado de modo supra-modal é o espaço da própria ação. ${ }^{17}$ Esse enredamento de diferentes modalidades perceptivas e da ação, como mostra a pesquisa com

12 MERLEAU-PONTY, 1945, p. 281-294. Em muitos aspectos, a análise de Merleau-Ponty da percepção aproxima-se da integração entre as diferentes modalidades perceptivas e entre percepção e ação que se visa aqui.

13 CAMPBELL, 1994, p. 48. Ver também a noção de "mecânica intuitiva", em PEACOCKE, 1993, e as observações de BREWER, 1999, p. 194-203.

14 BERMÚDEZ, 2003, em especial p. 51-63.

15 EVANS, 1982, p.157, n. 26; "Things without the mind". EVANS, 1985, p. 255.

16 MELTZOFF, 1993. O ajuste supra-modal da percepção ocorre também em outros animais; ver: PROUST, $1999 ; 2000$.

17 Ver BERMÚDEZ, 1995b; 2001. 
bebês, não depende da posse de conceitos, não é necessário que a entidade distante que constitui o foco de interesse e atenção caia sob algum conceito. Podemos ver aqui um análogo da Generality Constraint: um objeto percebido por uma determinada modalidade sensorial deve poder ser percebido por uma outra modalidade sensorial, ou pelo menos situado no espaço que inclui objetos percebidos por outras modalidades..$^{18}$

Se a integração da experiência é independente da posse de conceitos, não parece adequado portanto exigir a passagem a um nível conceitual para a caracterização de algo como parte da experiência. A idéia de que algo só possa fazer parte da experiência se puder ser utilizado como entrada para a atividade de aplicação de conceitos e raciocínios, como diz McDowell, não parece correta, se ao menos essa exigência corresponder à exigência de integração - a menos que a aplicação de conceitos e o sistema de raciocínio (concept-applying, and reasoning system) sejam independentes da aplicação de conceitos (e deveriam então ser redescritos num vocabulário neutro). Essa integração da experiência não é a mesma que a desejada por Evans e McDowell: CNCs parecem estar disponíveis para a integração de um modo que não implica a introdução de uma faculdade da espontaneidade.

Pode-se pensar que estamos diante de um problema terminológico: por que não decidir que conceitos são habilidades de reidentificação e de organização da experiência, de tal modo que seria claro que animais e bebês os possuem? Alva Noë aplica o vocabulário conceitual a todos os casos que Evans chamaria de teoria primitiva da percepção: conteúdos perceptivos entram na organização da ação, ou antes, a percepção é ela mesma parte da atividade da exploração do mundo, envolvendo atenção, interesses etc., e por essa razão devemos admitir pelo menos uma atividade "quase-conceitual" na organização da percepção. ${ }^{19} \mathrm{O}$ reconhecimento da importância desse ponto não depende da (tímida) extensão do uso do termo “conceito". Nenhuma decisão desse tipo resolveria o que está em jogo: a exigência de integração que levava CNCs ao pólo conceitualista pode ser satisfeita num ponto mais primitivo da filogenia e da ontogenia do que o que sugere a descrição de McDowell e em situações na

18 O recurso à noção de espaço aqui não é acidental: Strawson (Individuals), e em seguida Evans ("The Molyneux's Question") e outros, numa veia mais uma vez kantiana, argumentaram, pela ligação entre as noções de espaço e de objetividade, parte do que está em jogo aqui. Para a extensão da Generality Constraint além de animais que usam a linguagem, ver: PROUST, 1999; 2000. A interpretação da expressão "deve poder ser percebido" não é simples: pode-se perguntar qual o sentido de "deve" num domínio no qual o vocabulário normativo não tem aplicação clara, ou aplicação alguma. Pode-se pensar que se deve substituir "deve poder" por "pode" na frase acima. Talvez, considerações sobre a normatividade e sobre o interesse da continuidade entre seres humanos adultos e bebês e animais não lingüísticos feitas na última parte do texto apontem para uma solução (que deveria ainda ser desenvolvida).

19 NOË, 2002, p. 195 
nossa experiência cuja descrição não exige tampouco a utilização de um vocabulário conceitualista.

Essa capacidade de identificar um objeto percebido em diferentes modalidades sensoriais não depende da posse de um conceito sob o qual caia um tal objeto. Um objeto que sinto pelo tato é também um objeto que pode em princípio pode ser visto, que produziria um som se o tocasse de determinado modo, que deixaria de perceber em tal e tal circunstância etc., e isso quer eu tenha conceitos para aquilo que percebo, quer não. Existe contudo uma outra maneira de entender o que é em geral integrado na experiência como parte da atividade racional.

\section{III}

CNCs não estão isolados, e a conexão entre eles não demanda a posse de conceitos: a unificação supra-modal e as transições entre estados do sujeito que unificam a experiência podem ocorrer sem a posse de conceitos para tais conteúdos. Mas isso não significa que essa unificação, na medida em que é parte da experiência de seres dotados de linguagem, seja fechada a exigências que só podem aparecer num vocabulário conceitual. Voltemos ao exemplo familiar da percepção de nuanças de cores além da distinção conceitual. Vejo alguém pintando uma parede. Percebo que um lado está mais escuro que o outro e digo-lhe. Ele concorda e volta a pintar o lado mais claro. Nós dois pensamos que a parede deve ter uma cor homogênea e percebemos que esse não é o caso. Basta que concordemos com algo do tipo "este lado está mais escuro do que aquele", com algumas crenças e objetivos em comum, para que concordemos com a decisão a ser tomada.

Há duas condições para a compreensão e a coordenação de ações mútuas nestes casos: (i) que aquele que interpreta seja sensível às mesmas diferenças de cor que aquele cujas ações ou palavras interpreta e (ii) que o intérprete perceba aquele que interpreta como um agente racional, procurando atingir determinados fins e adequando suas ações para tanto de acordo com o modo como pensa ser o mundo que o cerca, tendo crenças e desejos logicamente organizados e sensíveis ao que percebe, fazendo inferências de maneira correta etc.

Sem a primeira condição, o interpréte não poderia perceber em relação a que traços do mundo aquele que age organiza suas ações. A razão pela qual o exemplo das cores é tão claro é que cada um de nós simplesmente percebe essas diferentes nuanças, e em torno de reações comuns se organizam nossas interações. Se por alguma razão dois indivíduos não puderem perceber as 
mesmas diferenças numa dada modalidade sensorial, por uma razão qualquer, e se não houver um outro ajuste possível (por uma diferença associada a uma outra modalidade, por exemplo), eles não podem coordenar suas ações em torno dessas diferenças, como é possível no caso do pintor de parede mencionado. Mas a compreensão e a coordenação mútua de ações dependem também da atribuição ao agente de um comportamento racional, como em qualquer outro caso. Sem ver o agente como racional, a compreensão do que ele faz não pode sequer começar: não há como entender o gesto de um pintor de parede de retocar um lado da superfície, senão atribuindo-lhe uma série de crenças e objetivos racionalmente conectados, de tal maneira que seu comportamento nos seja inteligível.

Não menos necessário é ver aquele que se interpreta agindo em relação ao mundo tal como o vemos. A percepção de diferenças entre as cores é parte do que atribuo àquele que interpreto, se isso for relevante para a compreensão do seu comportamento. Aqui, como em toda interpretação, o intérprete vê aquele que interpreta como sensível de maneira geral aos mesmos traços do mundo aos quais ele é sensível, como tendo crenças verdadeiras em relação ao mundo e como organizando seu comportamento em função dessas crenças. A essa percepção, ou antes às crenças cuja origem é essa percepção, aplica-se um padrão de racionalidade como em qualquer outra situação: sem pensar que o pintor de paredes vê as mesmas nuanças de cores que eu vejo e que suas crenças são causadas pelo que vê, não há como entender sua ação no mundo, ou mesmo vê-lo como agente.

$\mathrm{O}$ interesse de retomar esses temas davidsonianos aqui é que a crenças cujo conteúdo é em parte formado pela percepção de cores para as quais não temos conceitos se aplicam de maneira plena exigências de racionalidade, exigências que se aplicam a esses conteúdos mesmos para os quais não temos conceitos. A sensibilidade das crenças ao que se percebe e a postulação de um padrão de percepção comum são parte do que significa ver alguém agindo numa dada situação. Se percebo três nuanças de cores, $n^{l}, n^{2}$ e $n^{3}$, vejo que $n^{l}$ é mais escura do que $n^{2}$ e que $n^{2}$ é mais escura do que $n^{3}$; então sei que $n^{l}$ é mais escura do que $n^{3}$ e espero que todo agente racional, em condições semelhantes às minhas, também saiba que $n^{l}$ é mais escura do que $n^{3}$. Esse exemplo é de certa forma ambíguo, permetindo tanto uma leitura na qual percebo uma superfície contínua com essas três nuanças (e num certo sentido vejo, e não deduzo, que $n^{l}$ é mais escura que $n^{3}$ ), quanto a leitura na qual não posso comparar diretamente $n^{1}$ e $n^{3}$. As duas situações no entanto servem a meu propósito. $\mathrm{O}$ segundo ponto é claro, a transitividade na relação "ser mais escuro que" é um princípio racional que organiza nossas crenças perceptivas. A primeira situação 
não é menos parte da compreensão da ação no mundo: as crenças são causadas pelos mesmos objetos em mim e na pessoa que interpreto, e, se ela não fosse sensível de maneira geral aos mesmos traços que percebo, sua ação não seria para mim intelegível.

A aplicação de condições de racionalidade exige que pelo menos parte dos constituintes das crenças seja conceitual, no exemplo acima, a relação "ser mais escuro que", o que sugere que não há como aplicar tais condições a conteúdos que seriam inteiramente não conceituais. Isso não implica contudo que o conteúdo de crenças deva ser inteiramente conceitual para que tais condições se apliquem. A idéia mesma de que crenças possam ser assim constituídas, com componentes em parte conceituais, em parte não conceituais, se aceita, mostra por que falar em conteúdos não associados a conceitos. CNCs têm um papel análogo a conceitos em crenças inteiramente conceituais, conceitos que não hesitaríamos dizer serem o conteúdo de tais crenças, com condições de correção e possibilidade de erro de aplicação. O reconhecimento do caráter pelo menos parcialmente conceitual de toda crença é uma resposta possível a Davidson e McDowell, para quem é provavelmente sem sentido dizer que podemos aplicar rational constraints onde não há conceitos. ${ }^{20}$

A frases nas quais figuram tais conteúdos, é possível aplicar o que Evans chama de critério intuitivo de diferença entre pensamentos:

[...] uma frase $S$ tem um valor cognitivo diferente de uma frase $S$ ' apenas se for possível entender $S$ e $S^{\prime}$ e ter diferentes atitudes em relação a elas. ${ }^{21}$

É possível entender "isto é $F$ " e "aquilo não é $F$ " onde "isto" e "aquilo" são demonstrativos para respectivamente $n$ e $n$ ', tendo diferentes atitudes proposicionais em relação a essas sentenças, e isso é a indicação de que são pensamentos diferentes. Esse teste equivale a uma exigência racional sobre pensamentos constituídos pelo menos parcialmente por conteúdos para os quais não temos conceitos. Sentenças com CNCs participam da explicação racional do comportamento, com todas as exigências que isso acarreta.

A sensibilidade a diferenças entre cores é parte do papel causal da experiência perceptiva na constituição de crenças, da mesma forma que ver um coelho, ou ver que algo é vermelho. Pouco importa se somos capazes de

20 Esta estratégia permite também responder à crítica de Brewer, segundo a qual CNCs apresentariam conteúdos que não poderiam ser razões para o sujeito (BREWER, 1999, p. 157-169). CNCs podem perfeitamente figurar em razões para o sujeito, em inferências sobre as quais se aplicam condições que só se aplicam a razões para um indivíduo.

21 "[...] a sentence $S$ has a different cognitive value from a sentence $S$ ' just in case it is possible to understand $S$ and $S^{\prime}$ while taking different attitudes towards them." EVANS, 1982, p. 19. 
reconhecer outras instâncias de coelhos e de coisas vermelhas, mas hesitemos em dizer que vemos exatamente a mesma nuança de vermelho que observamos ontem. Por que essa diferença não é importante? Porque para a compreensão do comportamento deve-se levar em conta o que percebe aquele que se interpreta no momento em que age. Para entender o que faz um pintor de parede, devo ver o que ele vê no momento em que está agindo, assim como devo atribuir as crenças que são relevantes para a ação que interpreto, e não estender a atribuição de crenças a domínios irrelevantes para a compreensão de um curso específico de ação.

Trata-se de uma conseqüência da tese de Akeel Bilgrami sobre o que chama "Localidade do Conteúdo" (Locality of Content). ${ }^{22} \mathrm{O}$ conceito de água operativo na explicação do comportamento de alguém que procura água para beber não inclui todas as crenças que se pode associar a "água”. Por essa razão, diferenças de crenças entre dois indivíduos, por exemplo, sobre a composição química da água, não são importantes na explicação de seu comportamento, se ambos procuram matar a sede:

A explicação da ação sempre ocorre num nível muito mais localizado do que o nível de uma teoria do sentido. ${ }^{23}$

A extensão a outros contextos pode fazer surgir diferenças na individuação de conceitos, mas da extensão do contexto apenas, se extensão houver, virão as pressões que podem levar a identificar diferenças entre crenças. A razão pela qual capacidades discriminativas que não podem ser estendidas no tempo participam da explicação do comportamento da mesma forma que capacidades que podem ser estendidas - e portanto podem ser associadas a conceitos - é precisamente a localidade do conteúdo na explicação da ação.

A restrição no tempo da atribuição de conteúdos não implica a atomização temporal dos conteúdos que se atribui às crenças daquele que se interpreta; ao contrário, ao procurar identificar o que é relevante na explicação da ação, somos levados a falar de ações que se desenrolam no tempo. A descrição mesma de situações nas quais a atribuição de CNCs parece ser pertinente indica ações que se prolongam. Se a tese da localidade do conteúdo foi proposta para bloquear a extensão de contextos além do que é exigido pela explicação da ação, o reconhecimento mesmo desse tipo de exigência leva à recusa da atomozição temporal de conteúdos. Conteúdos atribuídos apenas no instante,

22 BILGRAMI, 1992.

23 "Action-explanation always takes place at a much more local level than the meaning-theoretic level", BILGRAMI, 1992, p. 11. 
que não pudessem ser utilizados na explicação de uma ação que dure no tempo (isto é, de qualquer ação, ou de quase qualquer ação), seriam tão irrelevantes para a prática explicativa na qual se encontram quanto conteúdos individuados no nível agregativo de uma teoria do sentido. Assim como manter a identificação de um indivíduo em diferentes situações implica uma capacidade que se mantém ao longo do tempo, seja ele contínuo ou não, as distinções que não são retidas pela memória têm alguma duração temporal, senão não poderiam participar da explicação da ação. ${ }^{24}$ Não há limites claros para a duração temporal de CNCs, mas isso não anula a diferença entre distinções retidas na memória e recrutadas em conceitos mais ou menos estáveis e distinções que são apresentadas apenas por indexicais, segundo a tese de McDowell. ${ }^{25}$

Duas observações sobre CNCs se fazem necessárias. A primeira é que embora a existência de distinções finas demais para serem retidas pela memória, que portanto não podem ser capturadas num vocabulário conceitual, pareça evidente (ela ser assim tratada por Evans não parece um movimento argumentativo ilegítimo), não é necessário que elas sejam as mesmas para todos. Talvez essa precisão seja ela mesma tão evidente quanto a que ela corrige, mas suas consequiências para a teoria da percepção em geral, e para CNCs em particular, devem ser explicitadas. A experiência envolve uma atividade, requer atenção e está conectada aos interesses e ao que sabe e acredita aquele que percebe. Essa organização da percepção permite a exploração seletiva da miríade de detalhes das situações nas quais nos encontramos. ${ }^{26}$ A dependência da percepção da atividade daquele que percebe leva Alva Noë a falar do seu caráter "quase-conceitual", como já foi dito:

[...] o que é visto depende da atividade da parte daqueles que percebem que é pelo menos quase-conceitual. A atenção parece ser direcionada pelos percipientes a partir da sua compreensão do sentido ou significado do que vêem. ${ }^{27}$

Uma segunda observação: CNCs aparecem em práticas explicativas, não são representações independentes do que o sujeito perceptivo toma como conteúdo de crenças que guiam suas ações. Não há sentido em se falar do conteúdo de um estado perceptivo, i.e., de um conteúdo que represente o mundo

24 Ver McDOWELL, 1994, p. 56-60.

25 McDOWELL, 1994, p. 57. Ver também: BREWER, 1999, p. 170-174.

26 Ver a crítica de Alva Noë aos scenario contents de Peacocke. NOË 2002, p. 191-193. O papel ativo da mente na percepção em geral é apresentado também em NOË, 2001.

27 "[...] what is seen depends on activity on the part of perceivers which is at least quasi-conceptual. Attention seems to be allocated by perceivers on the basis of an assessment of the meaning or significance of what they see." NOË, 2002, p. 193. 
como sendo de determinada forma, senão como o conteúdo de uma crença, ou de um estado que participe da explicação da ação de um sujeito, e que, portanto, seja um conteúdo para o sujeito da ação.

Essas observações estão ligadas, pois o papel da atenção, do interesse, da compreensão daquilo que se vê aparece precisamente na organização temporal da experiência e da ação no mundo. Um pintor de paredes pode não apenas ser capaz de perceber mais diferenças de nuanças de cores, ou de fazê-lo mais rapidamente e com mais precisão, como pode também ser capaz de retê-las na memória e ter um vocabulário para cores mais extenso (essas duas capacidades, embora ligadas, são elas mesmas distintas). Sua capacidade de distinção de nuanças de cores é aquela que se reflete no modo como organiza sua experiência e sua ação.

\section{IV}

Jérôme Dokic e Elisabeth Pacherie argumentam contra a tese conceitualista de McDowell, ligando o caráter indexical de CNCs e o papel que podem (ou não podem) desempenhar em inferências. Seu argumento central é que, distinções na percepção sendo mais finas do que as que podem ser retidas na memória, sempre é possível que uma dada distinção em conteúdos perceptivos se perca no tempo mesmo de uma inferência:

$\mathrm{Na}$ ausência de qualquer capacidade de reconhecimento associada a conceitos, como garantir que o mesmo conceito demonstrativo aparece em ambas as premissas? O único caso em que tal garantia pode ser dada é quando os conteúdos de a é colorido assim e b é colorido assim estão simultaneamente disponíveis para o sujeito na experiência perceptiva de tal modo que possa ter ambos presentes à atenção ao mesmo tempo. Assim que se obtêm as duas premissas separadamente, a garantia desaparece, pois, pela falta da capacidade de reconhecimento, o sujeito não poderá assegurar se os conceitos demonstrativos envolvidos nas duas premissas são os mesmos ou diferentes. O poder inferencial de tais conceitos é assim extremamente restrito. ${ }^{28}$

Esses conteúdos, sem dúvida, têm um potencial inferencial muito restrito e talvez sejam pouco úteis na construção de um conhecimento qualquer. $\mathrm{O}$

28 "In the absence of any genuine recognitional capacity associated with such concepts, how are we to ensure that the same demonstrative concepts figure in both premisses? The only case in which such insurance can be given is when the contents $a$ is coloured thus and $b$ is coloured thus are simultaneously available to the thinker in perceptual experience on such a way that he can attend to both at once. As soon as the two premisses are obtained separately, the warrant disappears, since, for lack of recognitional capacity, the thinker will not be in a position to ascertain whether the demonstratives concepts involved in the two premisses are the same or different. The inferential power of such concepts is therefore extremely restricted." DOKIC; PACHERIE, 2001, p. 199. Uma observação similar é feita já por David Kaplan. Cf. KAPLAN, 1989b, p. 588-589. 
argumento de Dokic e Pacherie ameaça seu papel na explicação do comportamento. Essa restrição aponta um limite para a estratégia de McDowell, porque a estabilidade no tempo de conteúdos perceptivos suficiente para que eles estejam disponíveis para o raciocínio, como pressuposto por McDowell, é uma hipótese empírica, dizem Dokic e Pacherie, e uma hipótese empírica falsa:

Para que esta tese seja falsificada, seria suficiente mostrar que duas nuanças de cor que estão pouco acima do limiar de discriminação perceptiva quando apresentadas simultaneamente, não seriam discriminadas de maneira confiável, se apresentadas sucessivamente. ${ }^{29}$

Como este é precisamente o caso, conteúdos perceptivos que estão pouco acima do limiar da capacidade de discriminação perceptiva só podem figurar em inferências se presentes à percepção.

Deve-se perguntar, contudo, qual é a conseqüência desse tipo de resultado para a compreensão do modo como CNCs podem figurar em inferências. Exemplos como o do pintor de paredes acima utilizam capacidades de reconhecimento que duram o tempo da coordenação e da execução de uma determinada série de ações: as distinções pertinentes dependem do uso de indexicais e talvez não possam ser retidas além do tempo que dura essa ação, mas duram o tempo suficiente para figurar em raciocínios e ser operatórias na execução da ação. $\mathrm{O}$ argumento poderia valer para outros casos e teria seu alcance restrito: em alguns casos, a solução de McDowell é válida, quando há uma capacidade de reconhecimento de curta duração, em outros casos, não. Os últimos seriam os casos para os quais a estratégia de McDowell falha.

Mas será esse o ponto da tese de McDowell? O importante na utilização de CNCs, ou ainda, num vocabulário neutro entre a posição conceitualista e a não conceitualista, de conteúdos indexicais, é que sejam operatórios na explicação de uma determinada ação. Conteúdos que correspondam a distinções que não possam ser retidas além do contato perceptivo com aquilo que se percebe simplesmente não entram na coordenação de ações, na interpretação da ação de um agente numa dada situação, na medida em que estas exigem o reconhecimento estendido no tempo dessas diferenças, e por essa razão não interessam à tese segundo a qual conteúdos indexicais podem figurar em inferências.

29 "For this claim to be falsified, it would be enough to show that two shades of colour that are just over the threshold of perceptual discrimination when simultaneously presented would not be reliably discriminated if presented in succession. " DOKIC; PACHERIE, 2001, p. 198. 
Mais uma vez, a tese da localidade do conteúdo nos ajuda esclarecer esse ponto. Testes que identificam os limites entre nossa capacidade de distinção perceptiva e nossa capacidade de reter tais distinções não são contextos nos quais conteúdos indexicais figuram em raciocínios como parte da explicação de cursos de ações. Pode-se conceder assim que determinadas distinções entre tonalidades de cores não são retidas pela memória o tempo necessário para uma inferência ou para a execução de uma ação qualquer. Mas por essa razão mesma elas nunca figuram em contextos nos quais tais conteúdos são atribuídos.

A crítica de Dokic e Pacherie tem um dilema a resolver: ou bem ela aponta situações nas quais conteúdos indexicais não podem participar de inferências, por não serem retidos na memória, mas então, por esta razão mesma, eles nunca foram parte de inferências, porque nunca participaram da explicação de ações, ou bem ela trata dos conteúdos que figuram em inferências efetivamente atribuídas a indivíduos, e então elas correspondem a capacidades de reconhecimento suficientes para tanto.

Esse dilema é contudo desconfortável também para o conceitualista: ao aceitar que existem conteúdos indexicais que não podem participar de inferências, parece difícil entender em que sentido eles podem estar disponíveis para a espontaneidade e, portanto, por que razão devem ser ditos conceituais. Ao dividir assim o terreno, o adepto da posição de McDowell ganha conteúdos indexicais relevantes para a prática explicativa, mas deve conceder que existem conteúdos não conceituais - aqueles para os quais o argumento para a disponibilidade para práticas inferenciais não está disponível. A vitória aqui talvez seja para o não conceitualista: se conteúdos indexicais podem não estar disponíveis para inferência alguma, e portanto não estar disponíveis para a espontaneidade, não há razão para não os considerar não conceituais.

Existe um outro tipo de argumento contra a tese de McDowell, o argumento da não transitividade. Imaginemos que $S$ perceba dois objetos $a^{I}$ e $a^{2}$ num mesmo instante e os julgue da mesma nuança de marrom:

[...] parece sempre possível a um sujeito racional acreditar que tudo que assim $a 1$ é

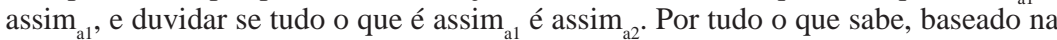
aparência perceptiva, pode haver uma amostra que é indistinguível de $\mathrm{a}^{2}$ mas distinguível de $\mathrm{a}^{1} .^{30}$

30 "[...] it seems always possible for a rational subject to believe that everything which is thus ${ }_{\mathrm{a} 1}$ is thus $\mathrm{a}_{\mathrm{a}}$, while doubting whether everything which is thus ${ }_{21}$ is thus $s_{2 .}$. For all she knows on the basis of perceptual appearance, there might be a sample which is indiscriminable from $a^{2}$ but discriminable from $a^{1}$." DOKIC; PACHERIE, 2001, p. 197. 
Esse raciocínio vale para quaisquer duas amostras de cores numericamente distintas (qualquer que seja o critério de distinção numérica entre duas amostras de cores), porque conteúdos indexicais são individuados pelas amostras às quais estão ligados. Se aceitarmos esse argumento e a tese conceitualista, a consequiência é que há tantos conceitos para cores quanto amostras de cores.

Distinções conceituais mais finas do que as diferenças fenomenológicas parecem ser uma conseqüência inaceitável da tese conceitualista. A resposta a esse argumento é de certa forma análoga à resposta anterior, mas explicita um ponto importante relativo à individuação de conteúdos. Segundo Dokic e Pacherie

[...] há um número infinito de CDCs para uma dada nuança, pois eles estão necessariamente ligados a amostras particulares. ${ }^{31}$

Conteúdos indexicais estão necessariamente ligados a amostras, porque, para quaisquer duas amostras, sempre é possível imaginar situações nas quais, pelo critério intuitivo de diferença, frases nas quais eles figuram tenham valor cognitivo diferente. Isso equivale a individuar conteúdos indexicais por aquilo que é designado, para caracterização mesma do que McDowell chama da "estrutura psicológica racionalmente organizada". ${ }^{32}$

Mas por que razão devemos aceitar essa individuação tão fina de pensamentos? Pela extensão ilimitada do contexto de atribuição de crenças, de tal modo que podemos conceber que o que não distinguimos numa dada situação poderia ser distinto numa outra situação. Mas justamente não há razão para essa extensão ilimitada de contextos, nem para a projeção de uma distinção encontrada numa dada situação sobre a atribuição de conteúdos numa outra situação. A atribuição de conceitos é sempre local, relativa à compreensão do comportamento racional de um agente numa determinada situação. Podemos, de certa forma, repetir a resposta anterior: conteúdos indexicais são potencialmente tão numerosos quanto as amostras às quais estão ligados, mas eles só são de fato conteúdos para um sujeito se aparecerem na explicação do comportamento racional de um agente, e não

31 "[...] there is an infinite number of DCCs for a given shade, since they are necessarily tied to particular samples." DOKIC; PACHERIE, 2001, p. 197. Ver também: PEACOCKE, 1989.

32 "Singular Thought and the Extent of the Inner Space". McDOWELL, 1998b, p. 233. A referência não é gratuita, pois esta individuação fina demais de pensamentos parece fazer pensamentos fregeanos (ou neo-fregeanos) equivalentes a proposições russellianas - embora seus constituintes sejam diferentes, a fineza de individuação é a mesma. Ora, o texto citado de McDowell é precisamente uma crítica à idéia de que proposições russellianas sejam adequadas à explicação da "estrutura psicológica racionalmente organizada". 
há razão para pensar que tais situações nos levem sempre, ou mesmo nos levem alguma vez, a uma individuação tão fina de conteúdos. Os resultados empíricos que Dokic e Pacherie utilizam para individuar finamente conteúdos indexicais podem ser utilizados no sentido oposto ao que eles pretendem: quanto mais próxima a distinção entre duas nuanças de cores estiver dos limites da nossa capacidade perceptiva, menor a chance de ela ser operativa em contextos nos quais se atribui de fato conteúdos indexicais a crenças de indivíduos.

Distinções que só podemos capturar por indexicais podem figurar nas nossas razões para agir, mesmo se não for possível estendê-las além de uma dada situação - de qualquer modo, a atribuição de conteúdos é sempre local, e nada impede que parte do que nela figura seja apenas local, isto é, não seja parte de um agregado de crenças que apareça em outras situações, em outro tipo de contexto. A diferença entre CNCs e conceitos é uma diferença de grau; Conceptuality comes in degrees, diz Alva Noë. ${ }^{33}$

\section{V}

CNCs figuram em inferências que explicam o comportamento e são eles mesmos dependentes da atividade cognitiva daquele que percebe, da sua atenção, do significado que atribui à experiência. Essas correções não levam de volta ao pólo conceitualista? Se à atribuição de CNCs se aplicam princípios normativos da racionalidade, se eles se estendem no tempo e são parte da atividade de compreensão da experiência e de atividades inferenciais, não devemos abandonar o expressão «não conceitual»? Dito de outra forma, se conteúdos perceptivos estão disponíveis à espontaneidade, não devemos considerá-los, por essa mesma razão, como plenamente conceituais, à maneira de McDowell? ${ }^{34}$

Se o argumento da fineza de individuação de conteúdos parece indicar uma diferença real entre conteúdos perceptivos, não é certo que ele não possa ser respondido pela solução de McDowell, que Michel Luntley chama da estratégia do seqüestro (kidnapping strategy). ${ }^{35}$ Além disso, não é claro se estamos diante de uma verdadeira questão filosófica, ou se se trata de um

33 NOË, 2002, p. 194

34 «Now it is true that the fine-grained capacities I have appealed to have a special character, which is marked by how demonstrative expressions would have to figure in linguistic expressions of them. But why should that prevent us from recognizing them as rationally integrated into spontaneity in their own way, so that they can simply take their place in my general framework?» McDOWELL, 1994, p. 58.

35 LUNTLEY, 2003, p. 402. 
problema terminológico, acerca daquilo a que se pretende aplicar o epíteto «conceitual». ${ }^{36}$

Mas assim como a teoria de McDowell não consiste apenas em uma reforma terminológica, a recusa em adotá-la também repousa em escolhas teóricas relevantes. Uma breve retomada do caminho feito até aqui, em torno das posições de McDowell e Evans, vai esclarecer minha posição. Para McDowell, todo conteúdo é conceitual, porque não existe nada na experiência que seja independente do exercício da faculdade de espontaneidade, ao passo que, para Evans, o conteúdo perceptivo é produzido independentemente de qualquer atividade da espontaneidade e, portanto, é não conceitual. ${ }^{37} \mathrm{O}$ conteúdo perceptivo independente da atividade da espontaneidade é, para Evans, comum a seres que têm linguagem e a seres que não a têm, ao passo que, para McDowell, existe uma ruptura já nos conteúdos perceptivos - parece só ter sentido aplicar o vocabulário kantiano da espontaneidade para os primeiros. ${ }^{38}$ Essa diferença inicial esclarece um ponto de acordo posterior entre os dois. Se para Evans o conteúdo da experiência é produzido independentemente dos conceitos que temos a nossa disposição, da nossa capacidade julgar e de fazer inferências, sua integração parece dever recorrer a um vocabulário que se aproxima do pólo conceitualista. McDowell concorda com a exigência de integração da experiência pela faculdade da espontaneidade - seu argumento contra CNCs é precisamente que nada pode ser assim integrado se não for conceitual desde o início.

Vimos, contudo, que a exigência da integração da experiência - o reconhecimento de um mesmo objeto percebido por diferentes modalidades e em diferentes ocasiões, a utilização do que é percebido na condução da ação etc. pode ser satisfeita, independentemente da posse de conceitos, por criaturas que não possuem a linguagem. O que nos afasta do pólo conceitualista é o caráter mais primitivo, tanto na ontogenia quanto na filogenia, da integração da experiência. Uma tal posição quanto à constituição da experiência leva naturalmente à aceitação de $\mathrm{CNCs}$, por um argumento que parece o inverso do de McDowell: se a experiência pode ser integrada independentemente da posse de conceitos, ela deve integrar conteúdos que são precisamente não conceituais. Esse mesmo argumento é novamente revertido, se considerarmos que à integração da experiência humana, e apenas a ela, se aplicam condições de racionalidade; talvez haja uma forma de integração que seja própria a seres 
com linguagem, e essa integração deve contar, desde início, com constituintes que lhe são próprios. Não é certo, no entanto, que o abandono de qualquer continuidade entre a experiência cuja compreensão é constitutivamente racional e outras formas de experiência e o isolamento da experiência humana de seus antecedentes filogenéticos e ontogenéticos sejam um bom resultado.

Existe, contudo, uma outra forma de descrever conteúdos não conceituais que evita pelo menos em parte essa oscilação e permite apresentar de maneira positiva o resultado desse percurso. À guisa de conclusão, vou apresentar duas teses e uma observação geral, que espero serem pelo menos parcialmente justificadas pelo que apresentei até aqui.

1. CNCs são apenas locais, não podem ser atribuídos senão por indexicais. Como já procurei argumentar, isso não implica a atomização temporal de CNCs. A contrapartida negativa dessa tese é a seguinte: dois CNCs distintos por exemplo, designando nuanças distintas de cores - não podem ser associados a conceitos de cores sem que se perca o critério intuitivo de diferença entre pensamentos. Se $n^{l}$ e $n^{2}$ são duas nuanças de cores que correspondem a CNCs, não existe nenhum conceito $F$ ( $F$ pertencendo ao vocabulário das cores) que possa ser associado a uma sem ser associado a outra, de forma que $S$ pode pensar que $n^{l}$ é $\mathrm{G}$, mas que $n^{2}$ não é $\mathrm{G}$, mas não pode pensar que $F$ é $G$, ' $F$ ' designando $n^{l}$, e entender esta frase, sem pensar, de $n^{2}$, que ele é $G$, aceitando que $F$ é $G$, ' $F$ ' designando $n^{2} .{ }^{39}$

Essa é uma retomada da tese de McDowell para a defesa de CNCs. Por que manter o epíteto «não conceitual»? A razão é que conceitos permitem a agregação de crenças ao longo da experiência, independentemente do contato perceptivo com a coisa designada pelo indexical. Crenças acerca de CNCs não são independentes da experiência do objeto designado. Isso não significa que ela seja isolada no tempo - esta é de qualquer forma uma imagem errônea da experiência -, nem que ela não possa ser designada depois, por expressões que remetem à experiência («aquele vermelho», «aquele perfume» etc.). Conceitos não funcionam dessa forma, eles podem se separar da experiência do objeto designado. $\mathrm{O}$ interesse de se manter a expressão «CNC» é o de reconhecer a diferença de papéis entre tais conteúdos e o de conceitos na organização da experiência ao longo do tempo, e em particular a capacidade de agregação de crenças acerca de traços reconhecíveis da experiência. A consequiência do argumento de Dokic e Pacherie - aceitar CNCs onde conteúdos indexicais não estão disponíveis para práticas inferenciais - deixa de ser um problema. Essa

39 Indexicais mistos («este $F$ ») podem ser associados a CNCs em razão do elemento indexical. A dependência de CNCs de contextos é apontada por KELLY, 2001; e BREWER, 1999. 
indicação geral sobre diferentes dinâmicas cognitivas permite apontar por que se manter o epíteto não conceitual. ${ }^{40}$

Uma consequiência dessa definição é que há uma distinção de grau entre CNCs e conteúdos conceituais. Não há uma linha clara de quando uma determinada distinção se torna suficientemente estável para ser separada da experiência imediata, ou da lembrança de tal experiência. Ao longo da vida de um mesmo indivíduo conceitos podem surgir, ou desaparecer e se dissociar das palavras, podemos hesitar acerca do caráter conceitual ou não de conteúdos. Isso é parte do que Alva Noë tem em mente, ao dizer que o caráter conceitual vem gradativamente.

Esse não é, contudo, o único interesse do comentário de Noë. Um outro ponto também é contemplado por esta definição: se conceitos (ou aquilo cuja dinâmica cognitiva é diferente de $\mathrm{CNCs}$ ) são o que permite a organização de expectativas e valorações acerca de traços da experiência independentes do contato perceptivo com aquilo em relação a que se tem expectativas e que se avalia de tal ou tal modo, certos traços de conceitos não são exclusivos do homem. Algo pelo menos análogo à distinção entre CNCs e conteúdos conceituais deve passar a barreira das espécies e das idades, da maneira já sugerida pelas diferentes formas de integração da experiência. Essa continuidade é contrabalançada pela minha segunda tese.

2. A ruptura entre a experiência humana e a experiência animal não se situa primariamente em componentes isolados, mas no tipo de organização que existe entre tais componentes. Condições de racionalidade impostas à compreensão do comportamento aparecem na integração da experiência. Isso não quer dizer que a única forma de constituição da experiência seja aquela que encontramos em seres dotados de linguagem, mas que o modo como rational constraints guiam a compreensão do comportamento humano é a origem da sua especificidade.

A imposição de critérios racionais para a compreensão da dinâmica é apresentada da seguinte forma por Davidson, ao argumentar pela irredutibilidade do mental a leis físicas:

[...] quando utilizamos os conceitos de crença, desejo etc., devemos estar preparados, à medida que se acumulam os dados, a ajustar nossa teoria à luz de considerações

40 Este ponto deveria ser desenvolvido, e explicitado o sentido da aplicação da expressão «dinâmica cognitiva» a CNCs (expressão cuja origem é KAPLAN, 1989a, p. 537). Interessa-me aqui unicamente indicar que não há agregação de crenças além do contato perceptual, ou do reenvio à situação de contato perceptual, em torno de CNCs, que são diferentes assim de outros tipos de conteúdo, que podemos dizer então conceituais. O uso que faço dessa expressão aproxima-se daquele feito por BREWER, 1999, p. 222. 
gerais (overall cogency): a idéia constitutiva de racionalidade controla parcialmente cada fase no desenvolvimento do que deve ser uma teoria em evolução. ${ }^{41}$

Reencontramos aqui a importância da faculdade da espontaneidade defendida por McDowell. Na medida em que CNCs participam da experiência humana, eles devem ser integrados em teorias guiadas pelo ideal constitutivo de racionalidade.

Mais uma vez, pode-se ter a impressão de que se trata apenas de uma reformulação terminológica da tese de McDowell. Não obstante a proximidade, acredito que há uma diferença importante, já apontada anteriormente. O reconhecimento de uma integração da experiência independente da faculdade da espontaneidade, assim como uma organização interna de seus elementos que, sob certos aspectos, é análoga para seres dotados de linguagem e para seres que não o são, permite o reconhecimento de um espaço conceitual para a continuidade natural entre o comportamento humano e outros tipos de comportamento. Parte do que deve entrar em teorias que preparam o terreno para a compreensão da emergência do pensamento, retomando o título de um importante texto de Davidson, é precisamente a integração da experiência antes da aplicação de um vocabulário racional. ${ }^{42}$

Donald Davidson aponta algumas condições para a conceitualização que estão presentes em animais sem linguagem e em bebês:

1) Com duas criaturas respondendo geralmente de maneira característica aos estímulos distais (distal stimuli), podemos falar do foco de suas respostas, a causa comum nos casos mais freqüentes.

2) Se pensamento houvesse, isto forneceria uma indicação óbvia para o conteúdo do pensamento.

3) Há espaço para o conceito de erro, que aparece quando existe divergência entre reações normalmente similares.

4) Finalmente, e talvez o mais importante, pois é o que mais facilmente deixamos de ver: transportamos a confiança na nossa noção de similaridade relevante para dentro do reino de interesses animais, reino ao qual ela seguramente pertence. ${ }^{43}$

41 «[...] when we use the concepts of belief, desire, and the rest, we must stand prepared to, as the evidence accumulates, to adjust our theory in the light of considerations of overall cogency: the constitutive idea of rationality partly controls each phase in the evolution of what must be an evolving theory.» "Mental Events». DAVIDSON, 1980, p. 223.

42 Embora procure nesta segunda tese indicar uma ruptura entre a experiência humana e a experiência animal (ou entre a experiência de animais que dominam a linguagem e animais pré- ou não lingüísticos), seria necessário, mais uma vez, seguindo Peacocke e Bermúdez, apontar a continuidade entre rational constraints e o que Peacocke chama de Overaching constraint (a ser comparada com a overall cogency que Davidson utiliza ao introduzir o ideal constitutivo de racionalidade). Ver: BERMÚDEZ, 1995b, p. 204; 2003.

43 «(1) With two creatures in general responding in characteristic ways to distal stimuli, we can speak of the focus of their responses, the common cause of the most frequent cases. (2) If thought were present, this would provide an obvious indication of the content of the thought. (3) There is a space for the concept of 
Se essas condições não são suficientes para o pensamento, elas já fizeram parte do caminho, e a organização de expectativas acerca da experiência e da reação dos outros, assim como o foco da ação comum de dois indivíduos, são em parte explicadas por algo que, cruzando a barreira das espécies e fases do desenvolvimento, é análogo à distinção entre o conceitual e o não conceitual para o homem. Talvez seja melhor guardar essas qualificações para a experiência humana, mas não me parece aconselhável criar um tal sistema de conceitos que torne difícil, senão impossível, ver semelhanças destas com outras formas de experiência.

O tom davidsoniano da conclusão pode parecer um tanto paradoxal para um texto que defenda CNCs. Seria muito longo defender essa posição, mas farei duas observações que talvez ajudem a diminuir essa sensação de estranhamento. ${ }^{44}$ A primeira é que o que falta a essas quatro condições para que possamos falar de pensamento, as idéias conectadas de crença e de erro, que surgem na triangulação, pode ser acomodado no quadro proposto, na construção de evolving theories às quais se impõem condições de racionalidade. A segunda é que falar de CNCs não implica a separação entre forma e esquema conceitual: não apenas não é o caso que a experiência seja massivamente não conceitual, mas apenas parte dela o é, ${ }^{45}$ como não há situação alguma na qual algum conteúdo possa ser atribuído à crença de um sujeito sem ser pelo menos parcialmente conceitual e, por essa razão, sem que a ele se apliquem condições de racionalidade. Não há espaço para uma experiência não interpretada, à qual se aplicaria em seguida um vocabulário sensível a tais condições.

3. Se a idéia de que podemos entender o que é o pensamento cortando completamente a ligação entre aquele que pensa e o mundo deve ser abandonada, isto é, se o internalismo não é uma opção viável, um movimento teórico similar deve nos levar a considerar com atenção o que é realmente externo em diferentes posições externalistas. Vou me limitar a uma breve observação sobre um ponto teórico subjacente a algumas discussões do texto. $\mathrm{O}$ contexto em que uma ação é compreendida não é determinado de maneira independente daquilo que é pertinente para aquele que age e do que pode ser percebido por aquele que interpreta.

error, which appears when there is a divergence in normally similar reactions. (4) Finally, and perhaps most important, since this is what we are most apt to miss: we have moved the reliance on our notion of relevant similarity into the realm of animal interests, where it surely belongs.» DAVIDSON, 2001, p. 12.

44 Esta conexão entre a utilização de CNCs na explicação do conteúdo do pensamento e o modo como o conteúdo figura na explicação da ação na teoria de Davidson (e de Dennett) aparece em PEACOCKE, 1989, p. 319-323.

45 A diferença entre se pensar que a experiência em geral é não conceitual e que ela é apenas localmente não conceitual revela diferentes compreensões da tese. McDowell, por exemplo, só aceita a primeira posição como coerente, embora a julgue falsa. Ver: McDOWELL, 1998a, p. 418-419. 
Este princípio já era operativo na recusa da individuação de CNCs designando nuanças de cores pelas amostras: o conteúdo atribuído a um indivíduo $S$ na explicação de um determinado curso de ação não é tudo o que pode distinguido por $S$, isto é, tudo que é biologicamente possível que $S$ distingua, ou tudo que se encontra nos limites da sua capacidade distintiva, detectada em situações experimentais determinadas, ou tudo o que um «agente onisciente» poderia distinguir, mas aquilo que é parte do que é para $S$ um constituinte da situação na qual se encontra. Claro que à medida que a ação progride, tais constituintes podem mudar, e não é necessário pensar que tudo que é parte da situação para $S$ é aquilo a que ele tem acesso conscientemente, ou no nível pessoal (em oposição ao que pode funcionar no nível subpessoal). Nada disso significa contudo que o contexto deva ser partido tão finamente quanto é possível, independentemente do curso de ações que se interprete. $\mathrm{O}$ que prentedo sugerir é que o contexto é determinado pela ação de $S$, pelo que ele faz e pelo que lhe acontece, e se não há limites predefinidos para o que pode entrar aqui, o contexto não funciona tampouco de maneira indefinida. Encontramos aqui uma motivação para a posição conhecida como neofregeana - a proximidade com Gareth Evans e John McDowell não é acidental. ${ }^{46}$ Vou terminar recorrendo a um outro neofregeano, Michael Luntley.

Esta compreensão do externalismo está em consonância, acredito, com o que Luntley chama de tese da mente vazia:

Tese da Mente Vazia: não precisamos de representações para pensar, pois pensar não é uma operação definida a partir de representações; é uma operação definida a partir de nossos encontros com o mundo. ${ }^{47}$

O que se compreende, aquilo sobre o que se impõem condições de racionalidade, para o que se requer conteúdos individuados de diferentes maneiras, não são representações, mas o comportamento. Cito mais uma vez Luntley:

46 A sensibilidade da posição neofregeana a argumentos internalistas aparece, por exemplo, na seguinte passagem de McDowell: «There is something gripping about the 'internalism' that is expressed here. The root idea is that one's epistemic standing on some question cannot intelligibly be constituted, even in part, by matters blankly external to how it is with one subjectively. For how could such matters be other than beyond one's ken? And how could matters beyond one's ken make any difference to one's epistemic standing?» "Criteria, Defeasability, and Knowledge». McDOWELL, 1998b, p. 390. É particularmente importante aqui a referência ao trabalho de Alva Noë.

47 «Empty Mind Thesis: we do not need representations in order to think, for thinking is not an operation defined over representations; it is an operation defined over our encounters with the world." LUNTLEY, 1997, p. 78. 
[...] a conhecida composicionalidade da nossa inteligência não é uma propriedade de um conjunto de entidades quase-lingüísticas, a composicionalidade da inteligência é uma propriedade de nossas ações. ${ }^{48}$

O que ele diz sobre a composicionalidade pode ser estendido às razões que existem para a atribuição de conteúdos, à sua organização e ao papel que desempenham na explicação da ação. Uma contrapartida dessa tese é a idéia de que contextos operativos para a compreensão de uma dada ação são o que encontramos no mundo no curso dessa ação. Se não podemos esperar entender o que é pensar e agir fazendo abstração dos contextos nos quais pensamos e agimos, não há tampouco compreensão do que são contextos fora do que é para nós pensar e agir.

\section{Referências}

BERMÚDEZ, José Luis. The Notion of a Nonconceptual Point of View. In: BERMÚDEZ, J. L.; MARCEL, A. J.; Eilan, N. (Ed.). The Body and the Self. Cambridge/ MA: MIT Press. 1995a. p. 153-173.

. Non conceptual content: From Perceptual Experience to Subpersonal Computational States. Mind and Language, 10, p. 333-369, 1995b. (Citado a partir da reimpressão em GUNTHER, York H. (Ed.). Essays on Nonceptual Content. Cambridge/ MA: MIT Press, 2003. p. 183-216).

. Practical Understanding $v s$ Reflective Understanding. Philosophy and Phenomenological Research, 57, p. 635-641, 1997.

Nonconceptual Self-Consciousness and Cognitive Science. Synthese, 129, p. 129-149, 2001.

Thinking Without Words. New York: Oxford University Press, 2003.

BILGRAMI, Akeel. Belief and Meaning. Oxford: Blackwell, 1992.

BREWER, Bill. Perception and Reason. Oxford: Oxford University Press, 1999.

CAMPBELL, John. Past, Space, and Self. Cambridge/MA: MIT Press, 1994.

DAVIDSON, Donald. Essays on Actions and Events. Oxford: Oxford University Press, 1980.

. Externalisms. In: KOTATKO, P.; PAGIN, P.; Segal, G. (Ed.). Interpreting

Davidson. Stanford: CSLI Publications, 2001. p. 1-16.

DOKIC, Jérôme; PACHERIE, Elisabeth. Shades and Concepts. Analysis, 61, p. 193202, 2001.

EILAN, Naomi. Molyneux's Question and the Idea of an External World. In: EILAN, N.; McCARTHY, R.; BREWER, B. (Ed.). Spatial Representation - Problems in Philosophy and Psychology. Oxford; Oxford University Press, 1993. p. 236-255.

48 «[..] the familiar compositionality of our intelligence is not a property of a quasi-linguistic set of entities, the compositionality of intelligence is a property of our actions.» LUNTLEY, 1997, p. 85. 
EVANS, Gareth. The Varieties of Reference. Oxford: Clarendon, 1982. Collected Papers. Oxford: Clarendon, 1985.

GUNTHER, York H. (Ed.). Essays on Nonceptual Content. Cambridge/MA: MIT Press, 2003.

KAPLAN, David. Demonstratives. In: ALMOG, J.; PERRY, J.; WETTSTEIN, H. (Ed.). Themes from Kaplan. Oxford: Oxford University Press, 1989a. p. 481-563. . Afterthoughts. In: ALMOG, J.; PERRY, J.; WETTSTEIN, H. (Ed.).

Themes from Kaplan. Oxford: Oxford University Press, 1989b. p. 565-614.

KELLY, Sean. The Nonconceptual Content of Perceptual Experience: Situation Dependence and Fineness of Grain. Philosophy and Phenomenological Research, 62, p. 601-608, 2001. (Reimpresso em Gunther 2003, p. 223-229).

LUNTLEY, Michael. Dynamic Thoughts and Empty Minds. European Review of Philosophy, DOKIC, J. (Ed.). - Cognitive Dynamics, 2, p. 77-103, 1997.

. Non-conceptual Content and the Sound of Music. Mind and Language,

18, p. 402-426, 2003.

MARTIN, M. G. F. Perception, Concepts, and Memory. The Philosophical Review, 101, p. 745-764, 1992.

McDOWELL, John. Mind and World. Cambridge/MA: Harvard University Press, 1994. . Reply to Commentators. Philosophy and Phenomenological Research,

58, p. 403-431, 1998a.

Press, 1998 b. . Meaning, Knowledge, and Reality. Cambridge/MA: Harvard University

MELTZOFF, Andrew. Molyneux's Babies: Cross-modal perception, imitation and the mind of the preverbal infant. In: EILAN, N., McCARTHY, R.; BREWER, B. (Ed.). Spatial Representation - Problems in Philosophy and Psychology. Oxford: Oxford University Press, 1993. p. 219-235.

MERLEAU-PONTY, Maurice. Phénoménologie de la Perception. Paris: Gallimard, 1945. (Coll. Tel.).

NOË, Alva. Experience and the Active Mind. Synthese, 129, p. 41-60, 2001.

. Is Perspectival Self-Consciousness Non-Conceptual?. The Philosophical

Quarterly, 52, p. 185-194, 2002.

PEACOCKE, Cristopher. Perceptual Content. In: ALMOG, J.; PERRY, J.; WETTSTEIN, H. (Ed.). Themes from Kaplan. Oxford: Oxford University Press, 1989. p. 297-329.

Intuitive Mechanics, Psychological Reality and the Idea of a Material Object. In: EILAN, N., McCARTHY, R.; BREWER, B. (Ed.). Spatial Representation - Problems in Philosophy and Psychology. Oxford: Oxford University Press, 1993. p. 162-176.

PROUST, Joëlle. Mind, Space and Objectivity in Non-Human Animals. Erkenntnis, 51, p. 45-58, 1999.

. Recalibration et Représentation Mentale. In: LIVET, P. (Ed.). De la Perception à l'Action. Paris: Vrin, 2000. p. 123-145. 
QUINE, W. V. The Ways of Paradox and other Essays - Revised and Enlarged Edition. Cambridge/MA: Harvard University Press, 1976.

STRAWSON, Peter F. Perception and Its Objects. In: MacDONALD, G. F. (Ed.). Perception and Identity - Essays presented to A. J. Ayer. Londres: Macmillan, 1979. p. 41-60. 